Informatika i sistemy upravleniya. - 2019. - No. 2(60). - P. 87-98.

Efanov D.V., Abdullaev R.B. (ruslan_0507@mail.ru)

Emperor Alexander I St. Petersburg state transport university

\title{
POLYNOMIAL CODES DESIGNED FOR DETECTING SOME SUBCLASSES OF NON- UNIDIRECTIONAL ERRORS IN DATA VECTORS
}

The article analyzes polynomial codes and their properties, related to error detection in data vectors. Generating polynomials are determined that allow to create polynomial codes with the property of detecting any symmetric and asymmetric errors in data vectors. The results of experiments with combinational circuits LGSynth ' 89 benchmarks sets are presented, confirming the theoretical results. The use of polynomial codes with the established properties makes it possible to take them into account when synthesizing testable discrete systems and their diagnostic support.

Keywords: polynomial code properties; error detection in data vectors; symmetrical error detection; asymmetrical error detection; testable discrete system.

DOI:10.22250/isu.2019.60.87-98

For citation:

Efanov D.V., Abdullaev R.B. POLYNOMIAL CODES DESIGNED FOR DETECTING SOME SUBCLASSES OF NON-UNIDIRECTIONAL ERRORS IN DATA VECTORS // Informatika i sistemy upravleniya. - 2019. - No. 2(60). - P. 87-98. 